\title{
MODELAGEM DO DESEMPENHO DAS INSTITUIÇÕES DE ENSINO SUPERIOR PRIVADAS: UM ESTUDO PARA O SEGMENTO DE PEQUENO E MÉDIO PORTE \\ http://dx.doi.org/10.5902/2318133848066
}

\author{
Diogo Martins Gonçalves de Morais ${ }^{1}$ \\ Júlio Francisco Blumetti Facó \\ Maria do Carmo Romeiro ${ }^{3}$
}

\begin{abstract}
Resumo
Por meio deste texto apresenta-se o resultado de um estudo pelo qual se propôs a investigar o desempenho das instituições de ensino superior privadas de pequeno e médio porte, sob a ótica da discussão de modelos organizacionais, por meio da elaboração e teste de um modelo robusto, com múltiplos fatores de influência sobre o desempenho organizacional, tais como orientação para o mercado, orientação para a aprendizagem, orientação empreendedora, liderança empreendedora, capital social e capital humano. O estudo contou com pesquisa quantitativa, utilizando uma amostra de 161 diretores e coordenadores de IES privadas de pequeno e médio porte do Estado de São Paulo, cujos dados foram tratados e analisados por meio de técnicas de análise multivariada. Concluiu-se que o desempenho das instituições de ensino superior privadas pode ser influenciado diretamente pela orientação empreendedora da instituição e indiretamente pela liderança empreendedora dos dirigentes.

Palavras-chave: gestão de instituições de ensino superior; desempenho organizacional; empreendedorismo no ensino superior.
\end{abstract}

\section{MODELING PERFORMANCE OF PRIVATE HIGHER EDUCATION INSTITUTIONS: A STUDY FOR THE SMALL AND MEDIUM SIZED SEGMENT}

\begin{abstract}
This study aims to investigate the performance of small and medium-sized higher education institutions from the perspective of discussing organizational models, through the construction and testing of a robust model, with the influencing factors on organizational performance, such as market orientation, learning orientation, entrepreneurial orientation, entrepreneurial leadership, social capital and human capital. The study included quantitative research, using a sample of 161 directors and coordinators of the small and medium-sized private $\mathrm{HEl}$ in the State of São Paulo, the data were analyzed and analyzed using multivariate analysis techniques. It was concluded that the
\end{abstract}

\footnotetext{
1 Fundação Salvador Arena, Brasil. E-mail: pro7113@cefsa.edu.br.

2 Universidade Federal do ABC, Brasil. E-mail: julio.faco@ufabc.edu.br.

3 Universidade Municipal de São Caetano do Sul, Brasil. E-mail: mromeiro@uscs.edu.br.
}

\begin{tabular}{|l|l|l|l|l|r|}
\hline Regae: Ver. Gest. Aval. Educ. & Santa Maria & v. 9 & n. 18 & Pub. contínua 2020 & p. 1-27
\end{tabular}


performance of private higher education institutions can be influenced directly by the entrepreneurial orientation of the institution and indirectly by the entrepreneurial leadership of the leaders.

Key-words: management of higher education institutions; organizational performance; entrepreneurship in higher education.

\section{Introdução}

os últimos vinte anos houve um crescimento significativo de instituições de ensino superior privadas no Brasil, promovendo maiores desafios aos mantenedores e gestores dessas instituições para a manutenção e desenvolvimento de seus negócios.

Por outro lado, os estudos sobre gestão organizacional têm constatado a contribuição de alguns componentes desse processo para a obtenção dos resultados da organização, tais como orientação para o mercado, orientação para a aprendizagem, orientação empreendedora, liderança empreendedora, capital social e capital humano.

Diante do exposto, apresenta-se a seguinte questão problema: considerando a complexidade dos objetivos de uma pequena e média instituição de ensino superior privada, que estão relacionados à entrega dos serviços contratados pelos estudantes, além do atendimento das expectativas da sociedade, no que se refere à garantia da qualidade da formação dos profissionais habilitados, assim como os desafios que qualquer empresa enfrenta, como a manutenção da vantagem competitiva, que modelo pode representar o desempenho no ambiente das Pmies privadas?

Com o intuito de responder esta questão o estudo teve o objetivo de elaborar e testar um modelo representativo do desempenho das Pmies privadas, a partir de uma plataforma de fatores potencialmente influenciadores, presentes nos estudos que investigam os fatores de influência sobre o desempenho organizacional em outros contextos, sob a ótica da discussão de modelos organizacionais.

Para tanto, percorreu-se um caminho que passou pela identificação dos fatores potencialmente influenciadores do desempenho das Pmies privadas, a identificação dos indicadores que operacionalizam o conceito de desempenho das Pmies privadas e, por fim, a análise das relações estruturais entre o desempenho e os fatores de influência no ambiente das Pmies privadas.

\section{Referencial teórico}

Nos últimos anos o Brasil tem experimentado mudanças significativas na oferta e concepção do ensino superior, que passou a contar, desde 1996, com o aumento significativo no número de IES privadas, conforme pode ser visto na figura 1. 
Figura 1 -

Crescimento do número de instituições de ensino superior no Brasil (1980-2017).

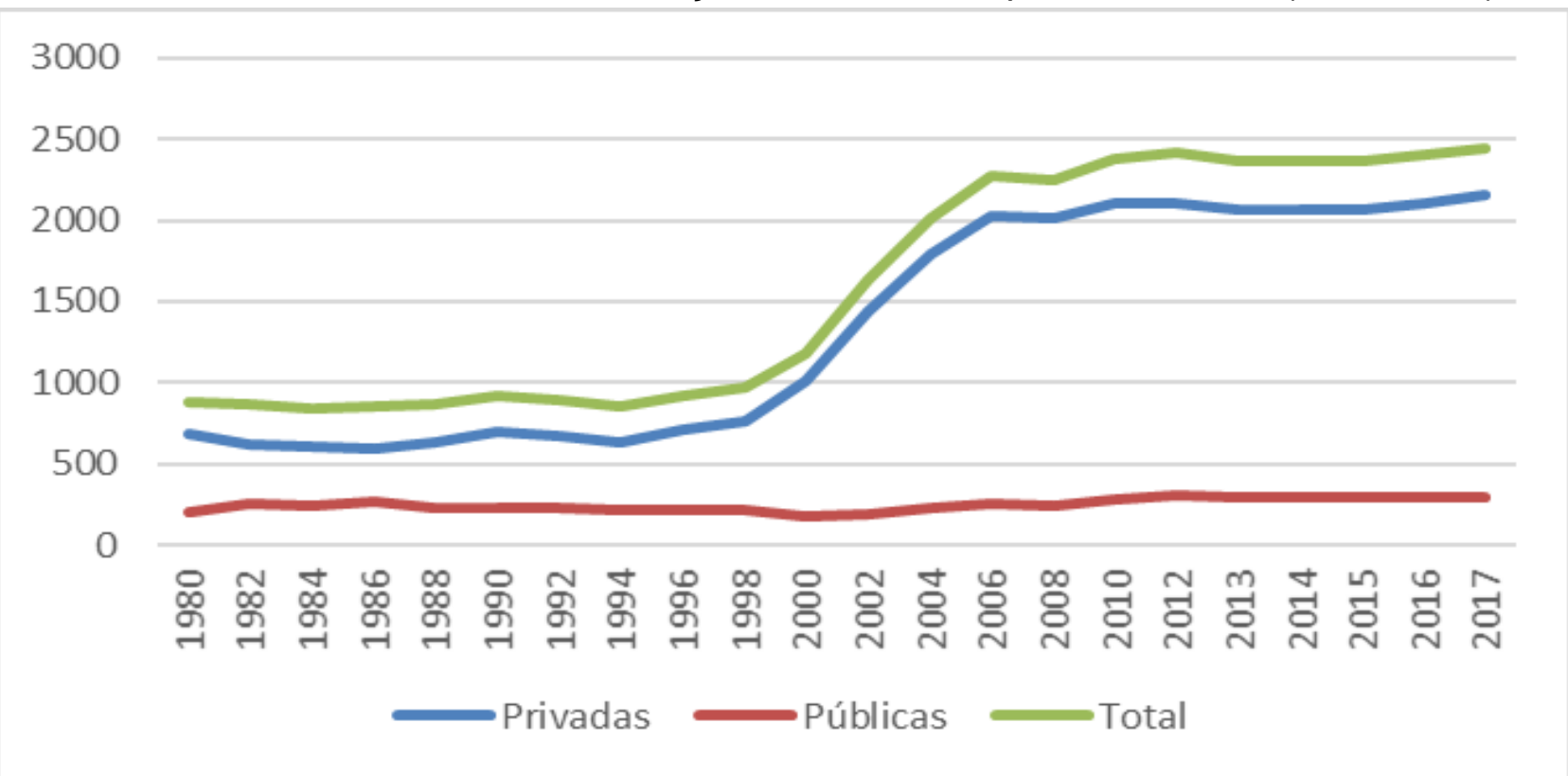

Fonte: www.portal.inep.gov.br/superior-censosuperior. Acesso em 20 nov. 2019.

Por outro lado os estudos sobre gestão organizacional têm constatado a contribuição de alguns componentes desse processo para os resultados da organização, dentre os quais, cultura de aprendizagem (Marsick, Watkins, 2003; Menezes, Guimarães, Bido, 2011); o capital social (Peng, Luo, 2000; Acquaah, 2007), o capital humano (GIMENO et al., 1997; Colombo, Grilli, 2005); o perfil empreendedor (Fontanelle, Hoeltgebaum, Silveira, 2006; Veit, Gonçalves Filho, 2007); a liderança empreendedora (Tarabishy et al., 2005; Fernandes e Santos, 2008); a orientação empreendedora (Grégoire et al., 2006; Schildt, Zahra, Sillanpää, 2006; Castanhar, Dias, Esperança, 2006; Souza Neto, Cordeiro, 2006; Martens, 2007; Rauch et al., 2004) e a orientação para o mercado (Fernandes, Santos, 2008; Reis Neto et al, 2013), podem representar vantagens competitivas.

Ao considerar os estudos que trataram a cultura de aprendizagem é possível observar que tal fator influencia o desempenho das organizações e se inter-relaciona com outros fatores, tais como a orientação para o mercado e o sucesso das inovações. No quadro 1 apresenta-se as dimensões e o número de variáveis utilizadas para a operacionalização do fator.

Quadro 1 -

Síntese dos estudos que relacionam a cultura de aprendizagem ao desempenho organizacional.

\begin{tabular}{|c|c|c|}
\hline Referências & $\begin{array}{c}\text { Dimensões e número de } \\
\text { variáveis }\end{array}$ & Relações validadas \\
\hline $\begin{array}{l}\text { Marsick; Watkins, } \\
\text { 2003; Yang, 2003; } \\
\text { Menezes; } \\
\text { Guimarães, Bido, } \\
\text { 2011. }\end{array}$ & $\begin{array}{l}\text { Oportunidades para a } \\
\text { aprendizagem contínua (3); } \\
\text { Questionamento e diálogo (3); } \\
\text { Colaboração e aprendizagem } \\
\text { em equipe (3); }\end{array}$ & $\begin{array}{l}\text { Conclui-se que a cultura de } \\
\text { aprendizagem influência o } \\
\text { desempenho organizacional. }\end{array}$ \\
\hline
\end{tabular}




\begin{tabular}{|c|l|l|}
\hline & $\begin{array}{l}\text { Sistemas para compartilhar a } \\
\text { aprendizagem (3); } \\
\text { Delegação de poder e } \\
\text { responsabilidade (3); } \\
\text { Desenvolvimento da visão } \\
\text { sistêmica da organização(3); } \\
\text { Estímulo à liderança } \\
\text { estratégica para a } \\
\text { aprendizagem (3). }\end{array}$ & \\
\hline $\begin{array}{c}\text { Baker; Sinkula, } \\
\text { 1999; Faleiro, 2001. }\end{array}$ & $\begin{array}{l}\text { Compromisso com a } \\
\text { aprendizagem (6); } \\
\text { Visão compartilhada (6); } \\
\text { Mente aberta (6). }\end{array}$ & $\begin{array}{l}\text { Conclui-se que há inter-relações entre } \\
\text { a orientação para aprendizagem, a } \\
\text { orientação para o mercado, as } \\
\text { inovações e há também relação entre o } \\
\text { desempenho organizacional e a } \\
\text { orientação para a aprendizagem. }\end{array}$ \\
\hline $\begin{array}{c}\text { Hurley; Hult, 1998; } \\
\text { Fernandes; Santos, } \\
\text { 2008. }\end{array}$ & $\begin{array}{l}\text { Unidimensional, com (8) } \\
\text { variáveis. }\end{array}$ & $\begin{array}{l}\text { Organizacional influencia a orientação } \\
\text { para o mercado e o sucesso das } \\
\text { inovações. }\end{array}$ \\
\hline
\end{tabular}

Fonte: resultados da pesquisa.

Ao considerar os estudos que trataram a orientação para o mercado é possível observar que tal fator influencia o desempenho das organizações e se inter-relaciona com outros fatores, tais como a orientação para a aprendizagem e o sucesso das inovações. No quadro 2 apresenta-se as dimensões e o número de variáveis utilizadas para a operacionalização do fator.

\section{Quadro 2 -}

Síntese dos estudos que relacionam a orientação para o mercado ao desempenho organizacional.

\begin{tabular}{|c|c|c|}
\hline Referências & $\begin{array}{l}\text { Dimensões e número de } \\
\text { variáveis }\end{array}$ & Relações validadas \\
\hline $\begin{array}{l}\text { Narver; Slater, 1990; } \\
\text { Jaworski; Kohli, } \\
\text { 1993; Caruana; } \\
\text { Ramaseshan, } \\
\text { Ewing, 1996; Baker; } \\
\text { Sinkula, 1999; } \\
\text { Faleiro, 2001; } \\
\text { Antoni, 2004. }\end{array}$ & $\begin{array}{l}\text { Escala denominada Markor } \\
\text { Inteligência de mercado (6); } \\
\text { Disseminação da inteligência } \\
\text { de mercado (5); } \\
\text { Resposta à inteligência de } \\
\text { mercado (9). }\end{array}$ & $\begin{array}{l}\text { Conclui-se que há inter-relações entre } \\
\text { orientação para o mercado, orientação } \\
\text { para a aprendizagem, as inovações. } \\
\text { Conclui-se também que a orientação } \\
\text { para o mercado influencia o } \\
\text { desempenho organizacional. } \\
\text { O estudo de Antoni (2004) não validou } \\
\text { a relação entre orientação para o } \\
\text { mercado e Desempenho. }\end{array}$ \\
\hline $\begin{array}{l}\text { Narver; Slater, 1990; } \\
\text { Reis Neto et al., } \\
2013 .\end{array}$ & $\begin{array}{l}\text { Orientação para a } \\
\text { concorrência (5); } \\
\text { Orientação para o consumidor } \\
\text { (2); } \\
\text { Coordenação interfunções (2). }\end{array}$ & $\begin{array}{l}\text { Conclui-se que a orientação para o } \\
\text { mercado influencia o desempenho } \\
\text { organizacional. }\end{array}$ \\
\hline $\begin{array}{l}\text { Deshpande; Farley, } \\
\text { 1998; Narver; Slater, } \\
\text { Maclachlan, 2004; } \\
\text { Fernandes; Santos, } \\
\text { 2008. }\end{array}$ & $\begin{array}{l}\text { Unidimensional com (10) } \\
\text { variáveis. }\end{array}$ & $\begin{array}{l}\text { Conclui-se que a orientação para o } \\
\text { mercado influencia o sucesso das } \\
\text { inovações e o desempenho } \\
\text { organizacional. }\end{array}$ \\
\hline
\end{tabular}

Fonte: resultados da pesquisa. 
Ao considerar os estudos que trataram a orientação empreendedora é possível observar que tal fator influencia o desempenho das organizações e se inter-relaciona com outros fatores, tais como a orientação para a aprendizagem e o sucesso das inovações.

Além disso, observa-se que a orientação empreendedora modera a relação entre a orientação para o mercado e o desempenho por meio das dimensões proatividade e assunção aos riscos. No quadro 3 apresenta-se as dimensões e o número de variáveis utilizadas para a operacionalização do fator.

\section{Quadro 3 -}

Síntese dos estudos que relacionam a orientação empreendedora ao desempenho organizacional.

\begin{tabular}{|c|l|l|}
\hline Referências & \multicolumn{1}{|c|}{$\begin{array}{c}\text { Dimensões e número de } \\
\text { variáveis }\end{array}$} & \multicolumn{1}{c|}{ Relações validadas } \\
\hline $\begin{array}{c}\text { Covin; Slevin, 1989; } \\
\text { Covin; Slevin, 1990; } \\
\text { Lumpkin; Dess, } \\
\text { 1996; Reis Neto et } \\
\text { al, 2013. }\end{array}$ & $\begin{array}{l}\text { Inovatividade (2); } \\
\text { Proatividade (2); } \\
\text { Assunção aos riscos (2). }\end{array}$ & $\begin{array}{l}\text { Conclui-se que a orientação } \\
\text { empreendedora modera a relação entre } \\
\text { a orientação para o mercado e o } \\
\text { desempenho por meio das dimensões } \\
\text { proatividade e assunção aos riscos. } \\
\text { Não se observou moderação da } \\
\text { dimensão inovatividade. }\end{array}$ \\
\hline $\begin{array}{c}\text { Naman; Slevin,1993; } \\
\text { Fernandes; Santos, } \\
\text { 2008. }\end{array}$ & $\begin{array}{l}\text { Cnidimensional com (8) } \\
\text { empreendedora influencia a }\end{array}$ \\
\hline variáveis. & $\begin{array}{l}\text { aprendizagem organizacional, o } \\
\text { sucesso das inovações e o } \\
\text { desempenho organizacional. }\end{array}$ \\
\hline
\end{tabular}

Fonte: resultados da pesquisa.

Ao considerar os estudos que trataram o perfil empreendedor dos líderes é possível observar que, embora os estudos de Schmidt e Bohnenberger (2009) mostrem que o perfil empreendedor do líder se mostra insuficiente para o entendimento dos antecedentes do desempenho de uma organização, Fontanelle, Hoeltgebaum e Silveira (2006), por meio de outra escala e noutro contexto, obtiveram relação positiva para o perfil empreendedor sobre o desempenho. Pelo quadro 4 apresenta-se as dimensões e 0 número de variáveis utilizadas para a operacionalização do fator.

Quadro 4 -

Síntese dos estudos que relacionam o perfil empreendedor ao desempenho organizacional.

\begin{tabular}{|c|l|l|}
\hline Referências & \multicolumn{1}{|c|}{$\begin{array}{c}\text { Dimensões e número de } \\
\text { variáveis }\end{array}$} & \multicolumn{1}{c|}{ Relações validadas } \\
\hline $\begin{array}{c}\text { Schmidt; } \\
\text { Bohnenberger, } \\
2009 .\end{array}$ & $\begin{array}{l}\text { Auto realização (5); } \\
\text { Liderança (4); } \\
\text { Planejamento (3); } \\
\text { Inovação (3); } \\
\text { Propensão a assumir riscos } \\
\text { (4); Socialização (3). }\end{array}$ & $\begin{array}{l}\text { Conclui-se que apenas a dimensão } \\
\text { auto realização possui relação } \\
\text { significante com o desempenho } \\
\text { organizacional. }\end{array}$ \\
\hline $\begin{array}{c}\text { Mcclelland, 1961; } \\
\text { Fontanelle; } \\
\text { Hoeltgebaum e } \\
\text { Silveira, 2006. }\end{array}$ & $\begin{array}{l}\text { Unidimensional com (55) } \\
\text { variáveis. }\end{array}$ & $\begin{array}{l}\text { Conclui-se que os gestores que } \\
\text { possuem características } \\
\text { empreendedoras mais desenvolvidas } \\
\text { também possuem melhor desempenho. }\end{array}$ \\
\hline
\end{tabular}

Fonte: resultados da pesquisa. 
Segundo Tarabishy et al (2005) quanto maior o grau de liderança dos dirigentes, maior será a orientação empreendedora das empresas dirigidas. Além disso, Fernandes e Santos (2008) constataram que a liderança influencia positivamente na orientação empreendedora, que por sua vez influencia positivamente o desempenho organizacional. Pelo 1uadro 5 apresenta-se as dimensões e o número de variáveis utilizadas para a operacionalização do fator.

Quadro 5 -

Síntese dos estudos que relacionam a liderança empreendedora ao desempenho organizacional.

\begin{tabular}{|c|c|c|}
\hline Referências & $\begin{array}{c}\text { Dimensões e número de } \\
\text { variáveis }\end{array}$ & Relações validadas \\
\hline $\begin{array}{c}\text { Tarabishy et al., } \\
2005 ; \text { Fernandes; }\end{array}$ & $\begin{array}{c}\text { Unidimensional com sete } \\
\text { Santos, 2008 }\end{array}$ & $\begin{array}{c}\text { Conclui-se que a liderança } \\
\text { varis. }\end{array}$ \\
\hline
\end{tabular}

Fonte: resultados da pesquisa.

Com base nos estudos de Acquaah (2007) o capital social dos principais líderes influencia o desempenho das organizações, mesmo que medido de maneiras diferentes. Com base nesses estudos Felício, Couto e Caiado (2014) pesquisaram a relação entre capital humano, capital social e desempenho mas não encontraram relação significante entre capital social e desempenho, como pode ser observado no quadro 6 .

Quadro 6 -

Síntese dos estudos que relacionam o capital social ao desempenho organizacional.

\begin{tabular}{|c|c|c|}
\hline Referências & $\begin{array}{c}\text { Dimensões e número de } \\
\text { variáveis }\end{array}$ & Relações validadas \\
\hline Acquaah, 2007 & $\begin{array}{c}\text { Indicador obtido pela opinião } \\
\text { dos líderes sobre a medida em } \\
\text { que suas redes de } \\
\text { relacionamentos sociais e } \\
\text { pessoais foram usadas para o } \\
\text { benefício de suas empresas, e } \\
\text { de que forma ocorreu tal } \\
\text { benefício. }\end{array}$ & $\begin{array}{c}\text { Conclui-se que o capital social } \\
\text { influencia o desempenho } \\
\text { organizacional, moderado pela } \\
\text { orientação estratégica de baixo custo e } \\
\text { de segmentação de mercado. }\end{array}$ \\
\hline $\begin{array}{l}\text { Felício; Couto, } \\
\text { Caiado, } 2014 .\end{array}$ & $\begin{array}{c}\text { Status (4); } \\
\text { Vínculos e apoio familiar (4); } \\
\text { Cumplicidade (3); } \\
\text { Relações pessoais (5); } \\
\text { Relações sociais (4). }\end{array}$ & $\begin{array}{c}\text { Conclui-se que o capital social } \\
\text { influencia o capital humano, mas não } \\
\text { influencia o desempenho } \\
\text { organizacional. }\end{array}$ \\
\hline
\end{tabular}

Fonte: resultados da pesquisa.

O estudo de Felício, Couto e Caiado (2014), apresentado no quadro 7, constatou que o capital humano dos executivos principais de uma empresa influencia o capital social destes mesmos executivos e o desempenho da empresa. 
Quadro 7 - Síntese dos estudos que relacionam o capital humano ao desempenho organizacional.

\begin{tabular}{|c|l|l|}
\hline Referências & \multicolumn{1}{|c|}{$\begin{array}{c}\text { Dimensões e número de } \\
\text { variáveis }\end{array}$} & \multicolumn{1}{c|}{ Relações validadas } \\
\hline $\begin{array}{c}\text { Felício; Couto e } \\
\text { Caiado, 2014. }\end{array}$ & $\begin{array}{l}\text { Conhecimento (4); } \\
\text { Experiência (6); } \\
\text { Proficiência profissional (4); } \\
\text { Habilidade cognitiva (4). }\end{array}$ & $\begin{array}{l}\text { Conclui-se que o capital humano } \\
\text { influencia o capital social e o } \\
\text { desempenho organizacional. }\end{array}$ \\
\hline
\end{tabular}

Fonte: resultados da pesquisa.

A revisão da literatura permitiu observar que não há consenso acerca dos fatores de influência sobre o desempenho, no entanto, evidenciou os elementos comuns dos diversos estudos realizados: a liderança, a orientação empreendedora, a orientação para a aprendizagem, a orientação para o mercado, o capital social e o capital humano.

Em relação do desempenho observou-se que há três dimensões utilizadas, que seguem a classificação de Januzzi (2005), como indicador-insumo, indicador-processo, indicador-resultado e indicador-impacto, e são organizados pelos autores como apresentados no quadro 8.

\section{Quadro 8 -}

Tipologia dos indicadores.

\begin{tabular}{|c|}
\hline Menezes, Guimarães e Bido (2011) \\
\hline $\begin{array}{l}\text { A produtividade média por empregado é maior que no ano passado: indicador-processo) } \\
\text { O tempo para colocar no mercado os produtos e serviços de energia é menor que no ano } \\
\text { passado: indicador-processo } \\
\text { O tempo de resposta para lidar com reclamações dos clientes externos é menor que no ano } \\
\text { passado: indicador-processo } \\
\text { A satisfação do cliente é maior que no ano passado: indicador-resultado } \\
\text { O número de sugestões implementadas pela empresa é maior que no ano passado: indicador- } \\
\text { processo } \\
\text { Na empresa, o número de indivíduos que aprendem novas habilidades é maior que no ano } \\
\text { passado: indicador-insumo }\end{array}$ \\
\hline Acquaah (2007) \\
\hline $\begin{array}{l}\text { Crescimento de vendas e receitas: indicador-resultado } \\
\text { Crescimento de renda ou lucros líquidos: indicador-resultado } \\
\text { Crescimento da produtividade: indicador-processo } \\
\text { Retorno sobre ativos: indicador-resultado } \\
\text { Retorno sobre vendas: indicador-resultado }\end{array}$ \\
\hline Felício, Couto e Caiado (2014) \\
\hline $\begin{array}{l}\text { O crescimento na participação de mercado: indicador-resultado } \\
\text { O crescimento das vendas: indicador-resultado } \\
\text { O crescimento dos lucros: indicador-resultado } \\
\text { O crescimento do tamanho da empresa: indicador-resultado } \\
\text { O desempenho geral: indicador-resultado } \\
\text { O desempenho no ano anterior: indicador-resultado }\end{array}$ \\
\hline Jaworski e Kohli (1993), Caruana, Ramaseshan e Ewing (1996) e Antoni (2004) \\
\hline $\begin{array}{l}\text { mpenho global, que foi medido pelo desempenho dos estudante } \\
\text { ado }\end{array}$ \\
\hline
\end{tabular}


Fernandes e Santos (2008)

Teve um aumento da parcela do mercado, em relação ao ano passado: indicador-resultado Aumentou o crescimento em vendas, em relação ao ano passado: indicador-resultado Foi mais lucrativa, em relação ao ano passado: indicador-resultado Aumentou seu tamanho, em relação ao ano passado: indicador-resultado Teve uma performance geral melhor, em relação ao ano passado: indicador-resultado

Cheruiyot e Maru (2013)

Os serviços desta universidade são muito melhores do que as concorrentes: indicadorprocesso

As facilidades desta universidade são muito melhores do que as concorrentes: indicadorinsumo

O programa acadêmico desta universidade é muito melhor do que das concorrentes: indicadorinsumo

As respostas dadas aos nossos problemas por esta universidade são muito melhores do que as concorrentes: indicador-processo

A imagem desta universidade é muito melhor do que a imagem das concorrentes: indicadorinsumo

A qualidade dos alunos desta universidade são muito melhores do que as concorrentes: indicador-insumo

A taxa de evasão desta universidade é muito menor do que as concorrentes: indicadorresultado

Se tivesse oportunidade, escolheria esta universidade para fazer novos cursos em um futuro: indicador-impacto

Eu recomendaria esta universidade como um lugar de estudo para meus amigos e familiares: indicador-impacto

\begin{tabular}{|c|c|}
\hline \\
\hline \multicolumn{2}{|c|}{$\begin{array}{l}\text { Ma e Todorovic (2011) } \\
\text { Nós somos reconhecidos pela sociedade e/ou pela indústria por nossa flexibilidade e poder de } \\
\text { inovação: indicador-impacto } \\
\text { Nosso departamento é altamente lembrado pela indústria: indicador-impacto } \\
\text { Muitos de nossos pesquisadores desenvolvem pesquisas em parceria com profissionais não } \\
\text { acadêmicos: indicador-processo } \\
\text { Nós temos grande número de spin-offs: indicador-impacto } \\
\text { Nossos estudantes de graduação alcançam postos elevados na indústria: indicador-impacto } \\
\text { Os pesquisadores de nossa instituição focam na pesquisa aplicada: indicador-processo }\end{array}$} \\
\hline Aghion et al (2010) & \\
\hline Número de patentes registradas: indicador-resultado & \\
\hline Santos (2008) & \\
\hline $\begin{array}{l}\text { Desempenho da IES na avaliação do MEC - IGC: indicador-resultado } \\
\text { Taxas de retorno: indicador-resultado } \\
\text { Índice de solvência: indicador-resultado } \\
\text { Índice de endividamento: indicador-resultado } \\
\text { Índice de eficiência: indicador-processo } \\
\text { Índices internacionais (EBITDA e Free Cash Flow): indicador-resultado } \\
\text { Aumento no número de alunos: indicador-resultado }\end{array}$ & \\
\hline
\end{tabular}

Fonte: elaboração própria.

Desta forma, ao considerar os indicadores-resultado presentes nos estudos registrados, assim como a aderência de cada indicador às áreas de resultados obtidas na análise do conceito desempenho, dadas pelos atributos econômicos, financeiros, mercadológicos, técnico-operacionais e sociais, realizou-se uma proposta inicial para a operacionalização do desempenho no ambiente das Pmies, apresentada no quadro 9. 
Quadro 9 -

Proposta inicial das variáveis do construto desempenho das Pmies.

\begin{tabular}{|c|c|c|}
\hline Dimensão acadêmica & $\begin{array}{c}\text { Dimensão administrativo- } \\
\text { financeira }\end{array}$ & Dimensão social \\
\hline $\begin{array}{c}\text { Desempenho da } \\
\text { PMIES na avaliação } \\
\text { do MEC e } \\
\text { desempenho dos } \\
\text { alunos no Enade, que } \\
\text { pode ser medido pelo } \\
\text { IGC }\end{array}$ & $\begin{array}{l}\text { Aumento do lucro; Redução da } \\
\text { inadimplência; Aumento de } \\
\text { matrículas; satisfação dos alunos } \\
\text { com a instituição, satisfação dos } \\
\text { coordenadores e diretores com o } \\
\text { pessoal técnico-administrativo e } \\
\text { satisfação dos alunos com os } \\
\text { professores. }\end{array}$ & $\begin{array}{c}\text { Aumento de publicações dos } \\
\text { professores; Quantidade de } \\
\text { projetos de extensão ofertados à } \\
\text { comunidade; Redução da evasão } \\
\text { escolar; Quantidade de alunos } \\
\text { em estágio; Empregabilidade dos } \\
\text { alunos. }\end{array}$ \\
\hline
\end{tabular}

Fonte: elaboração própria

A dimensão acadêmica para a descrição do desempenho de uma PMIES privada é operacionalizada pela medida da qualidade da formação dos alunos, da qualidade dos cursos e da IES, que podem ser resumidos em um único indicador, que é o Indice Geral de Cursos - IGC -, obtido anualmente pelo Sinaes. O IGC é calculado por IES e varia de 1 a 5 .

A dimensão administrativo-financeira para a descrição do desempenho de uma Pmies privada é operacionalizada pela medida da eficiência dos processos de gestão, obtida pela satisfação dos alunos com a instituição, satisfação dos coordenadores e diretores com o pessoal técnico-administrativo, satisfação dos alunos com os professores, e pela lucratividade da instituição, obtida pelo aumento do número de matrículas, aumento do lucro e redução da inadimplência.

A dimensão social para a descrição do desempenho de uma Pmies privada é operacionalizada pelo aumento de publicações dos professores, quantidade de projetos de extensão ofertados à comunidade, quantidade de alunos em estágio, pelo aumento da empregabilidade dos alunos e redução da taxa de evasão dos alunos.

\section{Hipóteses do estudo}

Ao considerar os estudos de Menezes, Guimarães e Bido (2011), na constatação da influência da cultura de aprendizagem, ou orientação para a aprendizagem, de acordo com Baker e Sinkula (1999), no desempenho organizacional, estabeleceu-se a seguinte hipótese para o estudo: $\mathrm{H} 1$ : a orientação para a aprendizagem influencia positivamente $\mathrm{e}$ diretamente o desempenho das PMIES privadas.

Ainda ao combinar os estudos citados, com aqueles desenvolvidos por Faleiro (2001), e Fernandes e Santos (2008) acerca das inter-relações existentes entre a orientação para aprendizagem, a orientação para o mercado e as inovações, observou-se em tais estudos que a orientação para a aprendizagem antecede a orientação para o mercado e o sucesso das inovações na influência sobre o desempenho. Fundamentado nestes estudos, estabeleceu-se a seguinte hipótese para o estudo: H2: a orientação para a aprendizagem influencia positivamente e indiretamente 0 desempenho das Pmies privadas, por meio da orientação para o mercado.

Ao observar a influência da orientação para o mercado sobre o desempenho organizacional, verificada nos estudos que envolvem a orientação para o mercado por meio da escala Markor, assim como as escalas de Narver e Slater (1990), ou Deshpande 
e Farley (1998), em destaque no quadro 9, estabeleceu-se a seguinte hipótese para o estudo: H3: a orientação para $\mathrm{o}$ mercado influencia positivamente e diretamente $\mathrm{o}$ desempenho das Pmies privadas.

Nos estudos de Naman e Slevin (1993), assim como em Fernandes e Santos, constatou-se que a orientação empreendedora influencia positivamente a orientação para a aprendizagem, assim como o desempenho organizacional. Diante dessas evidências estabeleceram-se as seguintes hipóteses: $\mathrm{H} 4$ : a orientação empreendedora influencia positivamente e indiretamente o desempenho das Pmies, por meio da orientação para a aprendizagem. H5: a orientação empreendedora influencia positivamente e diretamente $\mathrm{o}$ desempenho das Pmies privadas.

Embora o estudo de Fernandes e Santos (2008) tenha constatado que a influência da liderança seja pequena, segundo Tarabishy et al (2005), quanto maior o grau de liderança dos dirigentes, maior será a orientação empreendedora das empresas dirigidas. Desta forma estabeleceu-se a seguinte hipótese para o estudo: H6: a liderança dos diretores ou coordenadores influencia positivamente e indiretamente o desempenho das Pmies privadas por meio da orientação empreendedora.

Com base nos estudos de Felício, Couto e Caiado (2014) o capital humano dos principais líderes influencia o desempenho das organizações. Diante disso estabeleceu-se a seguinte hipótese para o estudo: H7: o capital humano dos diretores ou coordenadores influencia positivamente e diretamente o desempenho das pmies privadas.

O estudo de Felício, Couto e Caiado (2014) constatou que o capital humano dos executivos principais de uma empresa influencia o capital social dos mesmos. Fundamentado neste estudo estabeleceu-se a seguinte hipótese para estudo: H8: o capital humano dos diretores ou coordenadores influencia positivamente e indiretamente $o$ desempenho das Pmies privadas, por meio do capital social destes mesmos diretores ou coordenadores.

Embora os estudos de Felício, Couto e Caiado (2014) não tenham encontrado influência positiva entre capital social e desempenho, os estudos de Acquaah (2007) constataram que o capital social dos líderes influencia positivamente no desempenho das organizações. Desta forma estabeleceu-se a seguinte hipótese para estudo: H9: o capital social dos diretores ou coordenadores influencia positivamente e diretamente $\mathrm{o}$ desempenho das Pmies privadas.

Por fim, concluiu-se que as nove hipóteses estabelecidas sugerem um desenho para as inter-relações existentes entre os fatores mencionados e o desempenho organizacional, que foi avaliado por meio de pesquisa descritiva, junto a uma amostra de IES privadas de pequeno e médio porte.

\section{Procedimentos metodológicos}

$\mathrm{Na}$ operacionalização destas dimensões, assim como seus indicadores, foi realizada consulta à especialistas, tradução de algumas escalas da língua inglesa para a língua portuguesa, assim como posterior retradução, da língua portuguesa para a língua inglesa. 
A partir da definição dos indicadores constituintes do instrumento de pesquisa foi realizado um processo para a sua validação por meio da avaliação de juízes com o uso do coeficiente de validade de conteúdo - CVC -, pré-teste junto à uma amostra piloto de 24 diretores e coordenadores e análise fatorial exploratória aplicada aos dados coletados do pré-teste.

A partir daí foi realizado o planejamento amostral e efetivada a coleta dos dados primários da pesquisa quantitativa-descritiva, junto à amostra probabilística de 161 diretores e coordenadores de instituições de ensino superior privadas de pequeno e médio porte do Estado de São Paulo, 58\% do total de Pmies, que segundo a Abmes (2014), são IES com até 3.000 alunos.

Por fim, realizou-se uma segunda análise fatorial exploratória com os dados obtidos na pesquisa quantitativa-descritiva, com finalidade de confirmação da estrutura de cada construto envolvido e a modelagem de equações estruturais baseada em PLS, assim como a sua validação e discussão, que serão apresentadas a seguir, a começar pela elaboração das hipóteses do estudo, que foram elaboradas com base na síntese do referencial teórico.

Sobre as premissas subjacentes ao uso da AFE foram consideradas as orientações de Stevens (1996); Tabachnik e Fidell (2005); Hair et al(2009) e Garson (2014), conforme apresentado no quadro 10.

Quadro 10 -

Premissas subjacentes ao uso da análise fatorial exploratória.

\begin{tabular}{|c|c|}
\hline Premissas subjacentes & $\begin{array}{c}\text { Considerações a serem utilizadas nesta } \\
\text { pesquisa }\end{array}$ \\
\hline $\begin{array}{c}\text { Tamanho da amostra: Stevens (1996); } \\
\text { Tabachnik, Fidell (2005); Hair et al (2009) e } \\
\text { Garson (2014) }\end{array}$ & $\begin{array}{c}5 \text { a } 20 \text { casos por variável do maior construto } \\
\text { Stevens (1996) }\end{array}$ \\
\hline $\begin{array}{c}\text { Multicolinearidade: Stevens (1996); } \\
\text { Tabachnik, Fidell (2005) } \\
\text { Hair et al.(2009); Garson (2014) }\end{array}$ & $\begin{array}{c}\text { MSA (Measure of Sampling Adequacy) > 0,5 } \\
\text { Tabachnik, Fidell (2005); Garson (2014) }\end{array}$ \\
\cline { 2 - 2 } & $\begin{array}{c}\text { Kaiser-Meyer-Olkin > 0,5 } \\
\text { Tabachnik, Fidell (2005); Garson (2014) }\end{array}$ \\
\hline $\begin{array}{c}\text { Normalidade multivariada: } \\
\text { Stevens (1996); Tabachnik, Fidell (2005); Hair } \\
\text { et al.(2009); Garson (2014) }\end{array}$ & $\begin{array}{c}\text { Condição para os testes de significância: } \\
\text { Hair et al.(2009); Garson (2014) }\end{array}$ \\
\hline
\end{tabular}

Fonte: autor.

Para a verificação da aplicabilidade da AFE nesse conjunto de dados foram realizados o teste de adequação da amostra de Kaiser-Meyer-Olkin (KMO), a medida de adequação da amostra - MAS - e o teste de esfericidade de Bartlett, que indica se a matriz de correlações é uma matriz identidade.

Entre os métodos de rotação da matriz fatorial optou-se pelo método Varimax, uma vez que produz a melhor solução em situações de exploração de dimensões para um conjunto de variáveis incialmente selecionadas (Hair et al, 2009).

O método de extração utilizado foi o método de análise dos componentes principais, onde foi fixado o número de fatores, que no caso foi de um fator para cada construto, quando este era unidimensional, ou um fator para cada dimensão do construto, quando foi o caso. 
$\mathrm{Na}$ análise das comunalidades, que é a medida de quanto da variância da variável é explicada pelos fatores derivados pela AFE, optou-se pela exclusão das variáveis com comunalidades abaixo de 0,50 (Hair et al, 2009).

Para a avaliação de sua consistência interna utilizou-se o índice alfa de Cronbach (a). O software estatístico utilizado no tratamento dos dados foi mais uma vez o Statistical Package for the Social Sciences - SPSS -, versão 19.0.

Devido à grande quantidade de construtos e indicadores envolvidos no modelo proposto, em comparação aos estudos que foram referência nesta pesquisa, foi utilizada uma alternativa à modelagem de equações estruturais, que é baseada em covariâncias, pela Modelagem de equações estruturais baseada no método dos mínimos quadrados parciais - Partial Least Squares PLS - ou modelagem de equações estruturais baseado em variâncias (Hair et al., 2009), com o uso do software SmartPLS.

\section{Resultados e discussão}

A amostra evidencia uma participação de $30 \%$ de Pmies cujo tempo de existência não ultrapassa 12 anos e $72 \%$ de Pmies que não ultrapassa 20 anos de existência. A amostra possui tempo de existência médio de 23 anos, coeficiente de variação de $86 \%$ e tempo de existência mediano de 15 anos. Na tabela 1 apresenta-se os dados relativos ao tempo de existência das Pmies constituintes da amostra.

Tabela 2 -

Tempo de existência das Pmies.

\begin{tabular}{c|c|c}
\hline Idade da IES em anos & $n$ & $\%$ \\
\hline $04 \dashv 12$ & 48 & 30 \\
\hline $12+20$ & 67 & 42 \\
\hline $20 \dashv 28$ & 6 & 4 \\
\hline $28 \dashv 36$ & 2 & 1 \\
\hline $36 \dashv 44$ & 11 & 7 \\
\hline $44 \dashv 52$ & 13 & 8 \\
\hline $52 \dashv 60$ & 4 & 2 \\
\hline $60 \dashv 68$ & 2 & 1 \\
\hline $68 \dashv 76$ & 2 & 1 \\
\hline $76+84$ & 4 & 2 \\
\hline $84 \dashv 92$ & 1 & 1 \\
\hline $92 \dashv 100$ & 1 & 1 \\
\hline total & 161 & 100 \\
\hline
\end{tabular}

Fonte: autor.

A amostra evidencia que $60,5 \%$ das Pmies não possuem mais do que 788 alunos matriculados na graduação. A amostra possui número de alunos médio de 772 , coeficiente de variação de $83 \%$ e número de alunos mediano de 600 . Na tabela 2 apresenta os dados relativos ao número de alunos das Pmies constituintes da amostra. 
Tabela 3 -

Número de alunos das Pmies.

\begin{tabular}{c|c|c}
\hline Número de alunos & $\mathrm{n}$ & $\%$ \\
\hline $50 \dashv 296$ & 39 & 24 \\
\hline $296 \dashv 542$ & 36 & 22,5 \\
\hline $542 \dashv 788$ & 22 & 14 \\
\hline $788 \dashv 1034$ & 21 & 13 \\
\hline $1034 \dashv 1280$ & 11 & 7 \\
\hline $1280 \dashv 1526$ & 9 & 5,5 \\
\hline $1526 \dashv 1772$ & 5 & 3 \\
\hline $1772 \dashv 2018$ & 4 & 2,5 \\
\hline $2018 \dashv 2264$ & 4 & 2,5 \\
\hline $2264 \dashv 2510$ & 3 & 2 \\
\hline $2510 \dashv 2756$ & 0 & 0 \\
\hline $2756 \dashv 3002$ & 6 & 4 \\
\hline total & 160 & 100 \\
\hline
\end{tabular}

Fonte: autor.

O mapa representado na figura 2 ilustra a distribuição de Pmies no Estado de São Paulo, que apresenta assimetria na região Sudeste do Estado. É importante destacar que tal assimetria não está relacionada ao processo de amostragem, mas ao perfil da distribuição das Pmies no Estado, visto que a amostra foi obtida por amostragem sistemática, onde o sistema criado estava relacionado à ordem decrescente dos valores de IGC e não tinha nenhuma relação com a localização das Pmies. Registra-se que o volume de cada esfera apresentada na figura 2 é diretamente proporcional à frequência de Pmies da amostra.

Figura 2 -

Distribuição geográfica da Pmies constituintes da amostra.

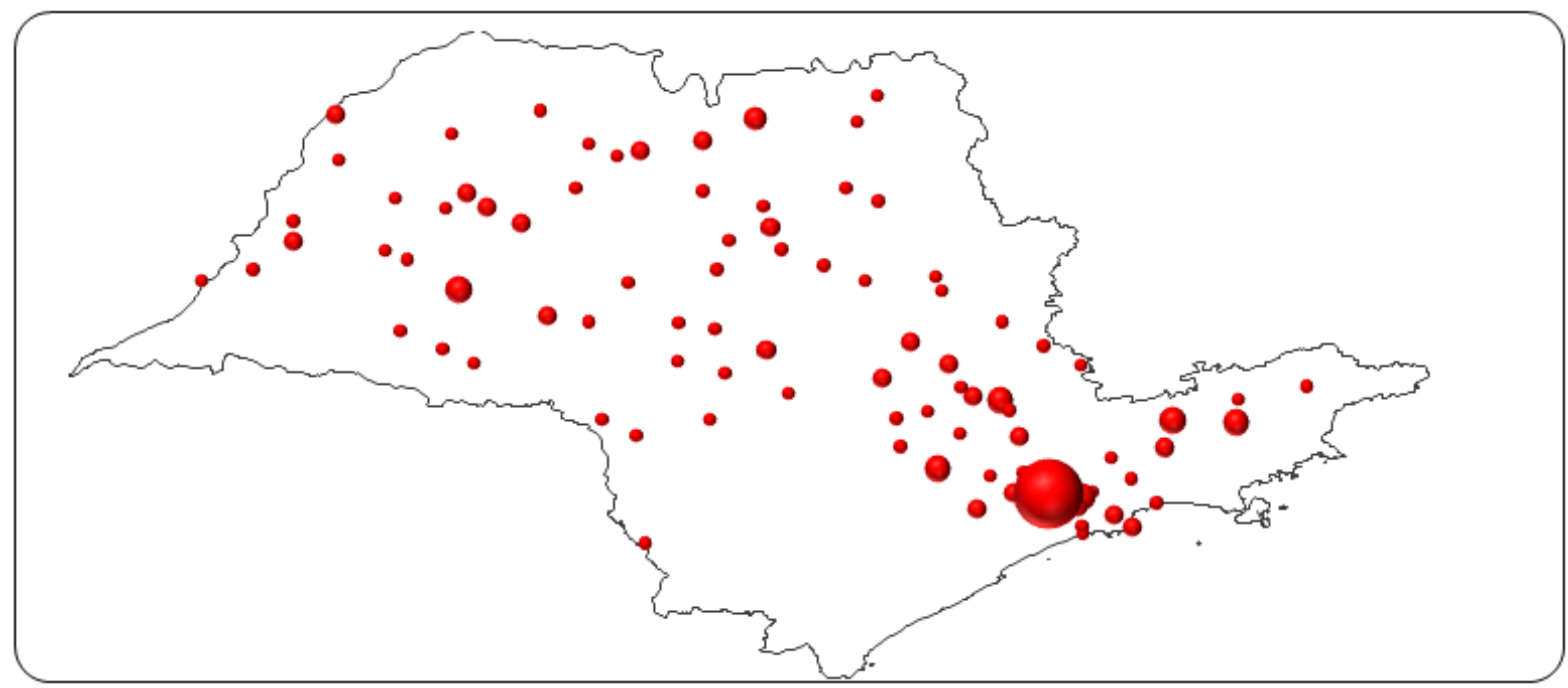

Fonte: autor. 
Ressalta-se que o público alvo da pesquisa foram as faculdades privadas de pequeno e médio porte existentes no Estado de São Paulo. Desta forma, nas regiões com espaços vazios no mapa podem existir faculdades de grande porte, mais de 3000 alunos, centros universitários ou universidades públicas ou privadas que não foram foco deste estudo.

Baseando-se na fundamentação teórica e nas hipóteses estabelecidas, propõe-se o desenho do modelo a ser testado no ambiente das Pmies privadas, ilustrado na figura 3.

Figura 3 -

Modelo estrutural planejado.

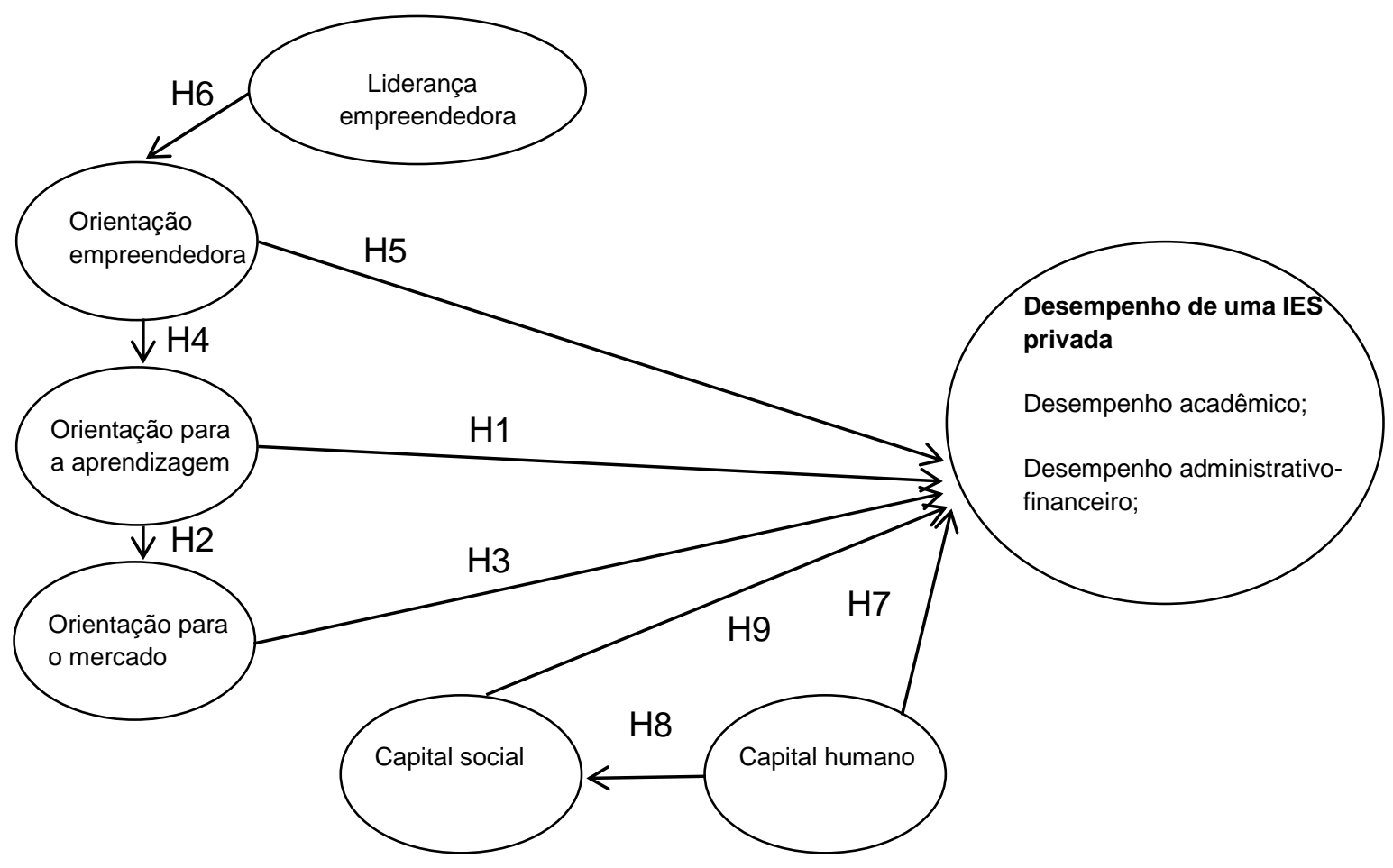

Fonte: autor.

Da mesma forma foi estabelecido o desenho do modelo representativo dos fatores de influência sobre o desempenho no ambiente das Pmies privadas, que envolve seis construtos que representam os fatores de influência sobre o desempenho, além do construto que representa o desempenho das Pmies privadas:

a) liderança empreendedora, operacionalizado por sete variáveis com base em Tarabishy et al (2005), traduzido para a língua portuguesa por Fernandes e Santos (2008);

b) orientação empreendedora, operacionalizado por seis variáveis distribuídas em três dimensões com base em Covin, Slevin (1989, 1990) e Lumpkin, Dess (1996), traduzidas por Reis Neto et al (2013);

c) orientação para o mercado, operacionalizado por dez variáveis com base em Narver, Slater, MacLachlan (2004), e Deshpande, Farley (1998), traduzida por Fernandes e Santos (2008) e adaptada pelo autor para o ambiente das Pmies privadas; 
d) orientação para a aprendizagem, operacionalizado por oito variáveis com base em Hurley e Hult (1998), traduzida por Fernandes e Santos (2008) e adaptada pelo autor para o ambiente das Pmies privadas;

e) capital social, operacionalizado por vinte variáveis distribuídas em cinco dimensões adaptadas para o ambiente das Pmies privadas pelo autor, a partir de Felício, Couto e Caiado (2014);

f) capital humano, operacionalizado por dezoito variáveis distribuídas em quatro dimensões e adaptadas para o ambiente das Pmies privadas a partir de Felício, Couto e Caiado (2014);

g) desempenho das Pmies privadas, operacionalizado por quinze variáveis distribuídas em três dimensões, e elaboração própria, a partir de evidências extraídas do referencial teórico.

A partir da estruturação das variáveis que operacionalizam cada um dos construtos foi realizada a análise do modelo estrutural e dos modelos de mensuração iniciais, apresentado na figura 4 e discutidos a seguir. 
Figura 4 -

Modelo estrutural e modelos de mensuração iniciais ${ }^{4}$.

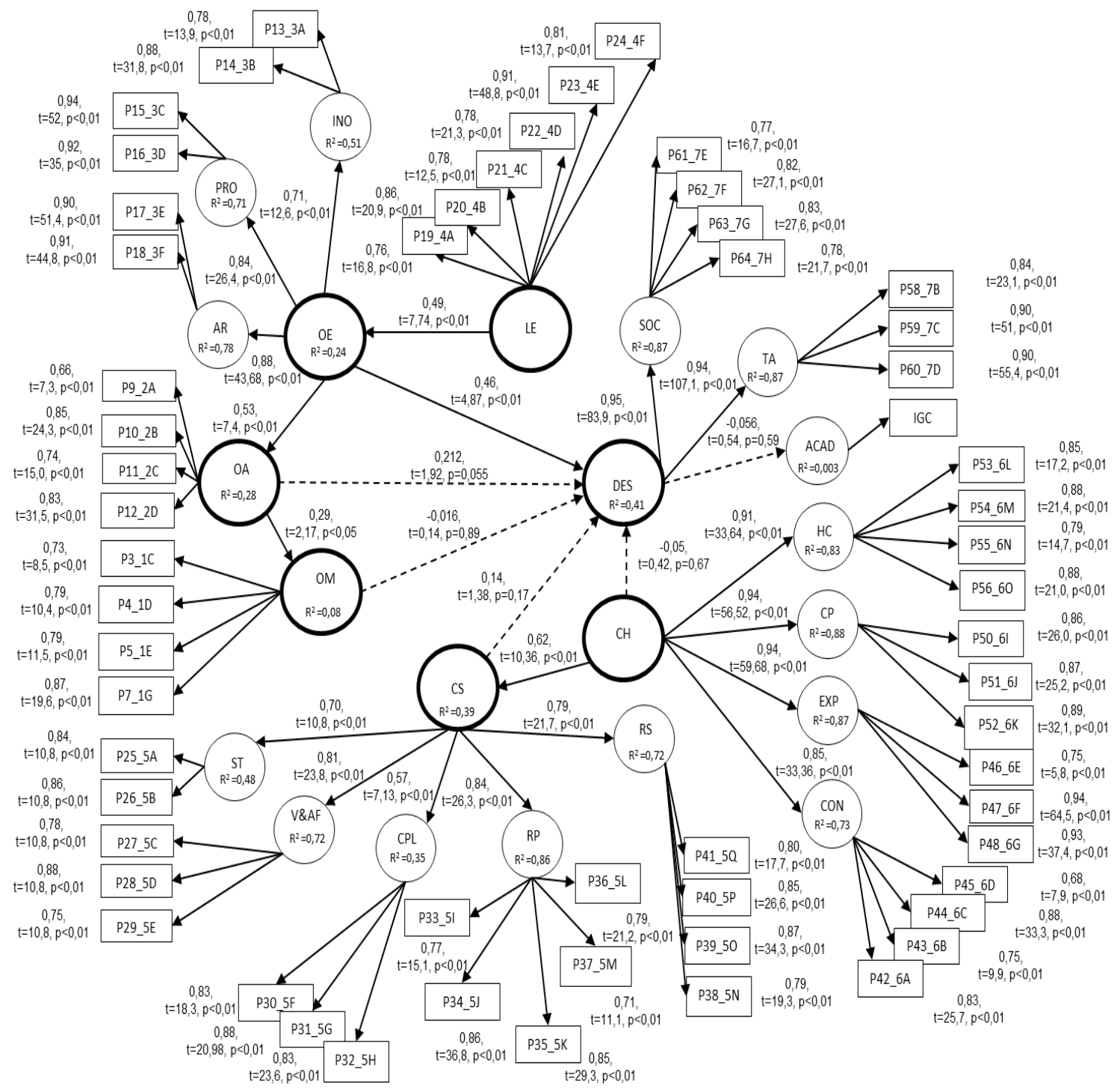

Fonte: resultados da pesquisa

O desenho do modelo apresenta as correlações entre as variáveis observáveis e as variáveis latentes nos modelos de mensuração, os valores dos coeficientes de determinação para todas as variáveis endógenas, os valores dos coeficientes de caminho da regressão linear entre as variáveis latentes e os testes de significância estatística de todas as relações. A partir daí realizou-se a validação do modelo, a começar pelos modelos de mensuração e, após os ajustes destes, o modelo estrutural (Ringle, Silva, Bido, 2010).

4 Nota: LE: liderança empreendedora; OE: orientação empreendedora; OA: orientação para a aprendizagem; OM: orientação para o mercado; $\mathrm{CH}$ : capital humano; CS: capital social e DES: desempenho; INO: inovatividade; PRO: proatividade; AR: assunção aos riscos; ST: status; V\&AF: vínculos e apoio familiar; CPL: cumplicidade; RP: relações pessoais; RS: relações sociais; CON: conhecimento; EXP: experiência profissional; CP: capacidade profissional; HC: habilidade cognitiva; ACAD: dimensão acadêmica; TA: dimensão técnico-administrativa; SOC: dimensão social.

Regae: Ver. Gest. Aval. Educ $\quad$ Santa Maria $\quad$ v. 9 n. 18 Pub. contínua 2020

p. $1-27$ 
A primeira verificação relevante para avaliação dos modelos de mensuração foram as validades convergentes, que podem ser obtidas pelas variâncias médias extraídas AVE -, e a segunda verificação relevante para a avaliação dos modelos de mensuração foram as consistências internas, dadas pelo alfa de Cronbach (ac), e confiabilidades compostas (cc) de cada uma das variáveis latentes. No quadro 11 apresenta-se os resultados da avaliação do modelo.

Quadro 1 -

Variância média extraída, confiabilidade composta e consistência interna.

\begin{tabular}{|c|c|c|c|c|}
\hline \multicolumn{2}{|c|}{ Variáveis latentes: construto/dimensões } & AVE & $\mathrm{CC}$ & ac \\
\hline \multicolumn{2}{|c|}{ Orientação para o mercado } & 0,638 & 0,875 & 0,812 \\
\hline \multicolumn{2}{|c|}{ Orientação para a aprendizagem } & 0,600 & 0,856 & 0,779 \\
\hline \multicolumn{2}{|c|}{ Orientação empreendedora } & 0,534 & 0,870 & 0,818 \\
\hline $\operatorname{dim} .1$ & Inovatividade & 0,688 & 0,815 & 0,554 \\
\hline $\operatorname{dim} .2$ & Proatividade & 0,867 & 0,929 & 0,847 \\
\hline $\operatorname{dim} .3$ & Assunção aos riscos & 0,816 & 0,899 & 0,775 \\
\hline \multicolumn{2}{|c|}{ Liderança empreendedora } & 0,668 & 0,923 & 0,901 \\
\hline \multicolumn{2}{|r|}{ Capital social } & 0,441 & 0,929 & 0,918 \\
\hline $\operatorname{dim} .1$ & Status & 0,722 & 0,838 & 0,615 \\
\hline $\operatorname{dim} .2$ & Vínculos e apoio familiar & 0,650 & 0,847 & 0,728 \\
\hline $\operatorname{dim} .3$ & Cumplicidade & 0,720 & 0,885 & 0,805 \\
\hline $\operatorname{dim} .4$ & Relações Pessoais & 0,634 & 0,896 & 0,854 \\
\hline $\operatorname{dim} .5$ & Relações Sociais & 0,683 & 0,896 & 0,845 \\
\hline \multicolumn{2}{|r|}{ Capital humano } & 0,569 & 0,951 & 0,943 \\
\hline $\operatorname{dim} .1$ & Conhecimento & 0,619 & 0,865 & 0,794 \\
\hline $\operatorname{dim} .2$ & Experiência & 0,661 & 0,884 & 0,822 \\
\hline $\operatorname{dim} .3$ & Capacidade profissional & 0,763 & 0,906 & 0,845 \\
\hline $\operatorname{dim} .4$ & Habilidade cognitiva & 0,720 & 0,911 & 0,870 \\
\hline \multicolumn{2}{|r|}{ Desempenho } & 0,493 & 0,895 & 0,862 \\
\hline $\operatorname{dim} .1$ & $\begin{array}{l}\text { Desempenho técnico- } \\
\text { administrativo }\end{array}$ & 0,662 & 0,885 & 0,826 \\
\hline $\operatorname{dim} .2$ & Desempenho social & 0,572 & 0,869 & 0,811 \\
\hline $\operatorname{dim} .3$ & Desempenho acadêmico & 1,000 & 1,000 & 1,000 \\
\hline
\end{tabular}

Fonte: resultados da pesquisa

Quando as AVE são maiores que 0,50 admite-se que o modelo de mensuração converge a um resultado satisfatório, porém, quando isso não ocorrer deve-se eliminar as variáveis observadas no modelo de mensuração que apresentar a AVE $<0,50$ (Fornell, Larcker, 1981).

Diante do valor da $A V E=0,441$ da variável latente capital social, foi realizado a exclusão das variáveis observadas constituintes deste construto, a partir da variável com a menor carga fatorial, de maneira sequencial, a saber: P29_5E, P36_5L, P37_5M e por fim P38_5N. No entanto, observou-se que o valor da AVE para o capital social passou de 0,441 para 0,442 após a primeira exclusão, porém, se manteve constante em 0,442 após as outras, o que denota a não convergência desse modelo de mensuração. 
Os valores acima de 0,60 para a ac e valores acima de 0,70 para a cc são considerados satisfatórios, embora valores superiores a 0,90 dos construtos capital social, capital humano, além da dimensão proatividade, sejam preocupantes (Hair et al, 2009).

A avaliação do modelo estrutural foi realizada por meio da avaliação dos coeficientes de determinação de Pearson (r2), que explica o quanto da variância das variáveis endógenas é explicada pelo modelo. Para a área de ciências sociais e comportamentais, Cohen (1988 apud Ringle, Silva e Bido, 2014 ) sugere que $r^{2}=2 \%$ seja classificado como efeito pequeno, $r^{2}=13 \%$ como efeito médio e $r^{2}=26 \%$ como efeito grande. Diante disso foi possível verificar que todas as variáveis latentes endógenas, com exceção da orientação para o mercado, possuem efeito grande.

No modelo estrutural teórico proposto as variáveis latentes que são exclusivamente exógenas são a liderança empreendedora e o capital humano.

Por meio de técnica de reamostragem - botstrapping - foi possível calcular testes $t$ student entre os valores obtidos na pesquisa e aqueles gerados pela re-amostragem para as correlações entre as variáveis observadas e variáveis latentes, além das variáveis latentes com as outras variáveis latentes (Ringle, Silva, Bido, 2014).

O desenho do modelo ajustado apresenta as correlações entre as variáveis observáveis e as variáveis latentes nos modelos de mensuração, os valores dos coeficientes de determinação para todas as variáveis endógenas, os valores dos coeficientes de caminho da regressão linear entre as variáveis latentes e os testes de significância estatística de todas as relações. Na figura 5 apresenta-se o modelo estrutural e modelos de mensuração ajustados. 
Figura 5 -

Modelo estrutural e modelos de mensuração ajustados ${ }^{5}$.

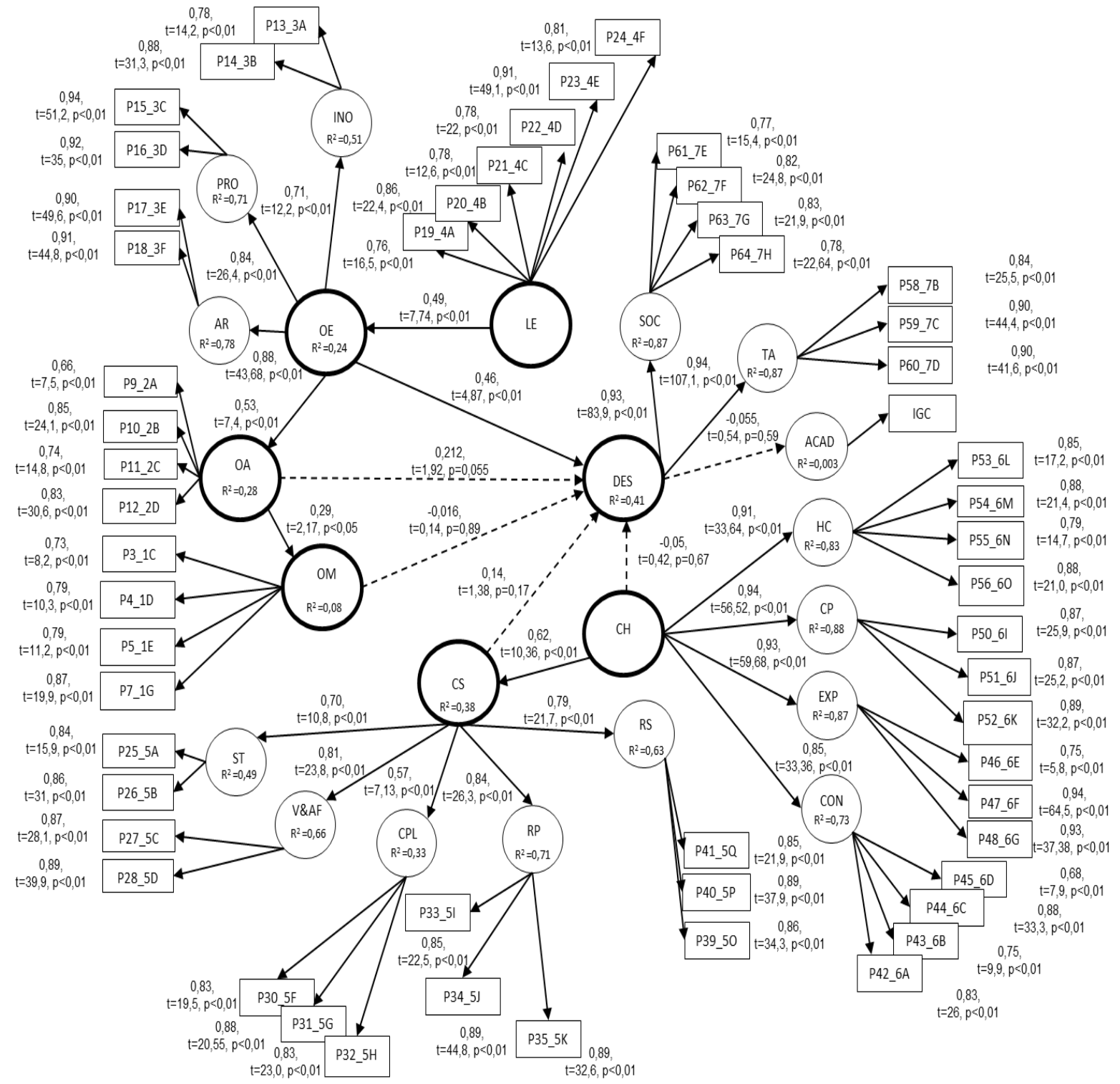

Fonte: resultados da pesquisa.

Os valores críticos do test $t$ bicaudal são de 1,65 (nível de significância = 10\%), 1,96 (nível de significância = 5\%), e 2,58 (nível de significância = 1\%) (HAIR et al., 2009).

A terceira verificação relevante para a avaliação do modelo estrutural foi a validade preditiva $\left(\mathrm{Q}^{2}\right)$, conhecido por indicador de Stone-Geisser. Como o próprio nome diz mede o quanto o modelo é capaz de prever. $O$ modelo perfeito, sem nenhum erro, possui $Q^{2}=$ 1, mas como critério de avaliação devem ser obtidos valores maiores que zero (HAIR et al., 2009).

5 Nota: LE: liderança empreendedora; OE: orientação empreendedora; OA: orientação para a aprendizagem; OM: orientação para o mercado; $\mathrm{CH}$ : capital humano; $\mathrm{CS}$ : capital social e DES: desempenho; INO: inovatividade; PRO: proatividade; AR: assunção aos riscos; ST: status; V\&AF: vínculos e apoio familiar; CPL: cumplicidade; RP: relações pessoais; RS: relações sociais; CON: conhecimento; EXP: experiência profissional; CP: capacidade profissional; HC: habilidade cognitiva; ACAD: dimensão acadêmica; TA: dimensão técnico-administrativa; SOC: dimensão social.

Regae: Ver. Gest. Aval. Educ $\quad$ Santa Maria $\quad$ v. 9 n. 18 Pub. contínua 2020

p. $1-27$ 
A quarta verificação para a avaliação do modelo estrutural foi a medida do tamanho do efeito $\left(\mathrm{f}^{2}\right)$ ou Indicador de Cohen. Esse indicador mede o quanto cada construto é útil. Por meio de um método iterativo cada construto é inserido e retirado do modelo, para que seja medida a sua utilidade. Valores de 0,02, 0,15 e 0,35 são considerados pequenos, médios e grandes, respectivamente (Hair et al., 2009).

A terceira e quarta verificação confirmaram que o modelo tem acurácia e que os construtos são importantes para o ajuste geral do modelo, no entanto, é possível observar que a Inovatividade $\left(\mathrm{f}^{2}=0,087\right)$ e o Status $\left(\mathrm{f}^{2}=0,17\right)$ têm efeito pequeno na explicação de suas respectivas variáveis endógenas: orientação empreendedora e capital social, respectivamente.

A quinta e última verificação para a avaliação do modelo estrutural foi o índice de adequação do modelo: GoF - Goodness of Fit. Segundo Wetzels et al (2009 apud Ringle, Silva, Bido, 2014), o valor mínimo de 0,36 é adequado para as áreas de ciências sociais e do comportamento. Desta forma podemos afirmar que o modelo estrutural, com $\mathrm{GoF}=0,38$, possui ajuste adequado.

Portanto, concluiu-se que o modelo teórico proposto está validado, com a ressalva da não convergência do modelo de mensuração do capital social.

\section{Efeitos diretos, indiretos e efeito total dos fatores de influência sobre o desempenho}

A partir da validação do modelo estrutural e ajustes dos modelos de mensuração abriu-se espaço para que fossem analisadas as formas com que estas relações ocorrem, por meio da análise dos efeitos diretos, indiretos e totais de cada um dos fatores de influência sobre o desempenho das PMIES.

Constatou-se que a orientação empreendedora possui relação direta, positiva e significante - ao nível de $1 \%$ - com a o desempenho das Pmies. A liderança empreendedora possui relação indireta, positiva e significante com o desempenho das Pmies, ao nível de significância estatística de $1 \%$, assim como a orientação empreendedora, ao nível de significância estatística de 5\%.

Embora a orientação para a aprendizagem não tenha efeito direto sobre o desempenho, ao nível de significância considerado mínimo neste estudo, que é de 5\%, e nem tampouco efeito indireto sobre o desempenho, constatou-se que o efeito total da orientação para a aprendizagem sobre o desempenho é positivo e significante ao nível de $5 \%$.

Por meio da análise dos efeitos diretos, indiretos e totais, obtidos do modelo ajustado validado, foi possível testar as hipóteses propostas.

$\mathrm{Na}$ primeira hipótese $(\mathrm{H} 1)$ afirmou-se que a orientação para a aprendizagem influencia positivamente e diretamente o desempenho das Pmies privadas. Observou-se que não há efeito direto significante da orientação para a aprendizagem sobre o desempenho $(\Gamma=0,212, t=1,92, p=0,055)$, no entanto, constatou-se que há uma relação efeito total - significante quando somados os efeitos diretos e indiretos da orientação para a aprendizagem sobre o desempenho $(\Gamma=0,207, t=2,02, p<0,05)$.

$\mathrm{Na}$ segunda hipótese (H2), afirmou-se que a orientação para a aprendizagem influencia positivamente e indiretamente o desempenho das Pmies privadas por meio da orientação para o mercado. Observou-se que não há efeito indireto da orientação para a 
aprendizagem sobre o desempenho $(\Gamma=-0,005, t=0,10, p=0,918)$, no entanto, registre-se que há uma relação positiva e estatisticamente significante ao nível de $5 \%$ entre a orientação para a aprendizagem e a orientação para o mercado $(\Gamma=0,289, t=1,924$, $p<0,05)$.

$\mathrm{Na}$ terceira hipótese $(\mathrm{H} 3)$ afirmou-se que a orientação para o mercado influencia positivamente e diretamente o desempenho das Pmies privadas. Observou-se que não há efeito direto da orientação para o mercado sobre o desempenho $(\Gamma=-0,016, t=0,14, p=$ $0,889)$.

$\mathrm{Na}$ quarta hipótese (H4) afirmou-se que a orientação empreendedora influencia positivamente e indiretamente o desempenho das Pmies por meio da orientação para a aprendizagem. Observou-se que há efeito indireto da orientação empreendedora sobre o desempenho, por meio da orientação para a aprendizagem, estatisticamente significante ao nível de $5 \%(\Gamma=0,11, t=1,91, p<0,05)$.

$\mathrm{Na}$ quinta hipótese (H5) afirmou-se que a orientação empreendedora influencia positivamente e diretamente o desempenho das Pmies privadas. Observou-se que há efeito direto da orientação empreendedora sobre o desempenho, estatisticamente significante ao nível de $1 \%(\Gamma=0,461, t=4,87, p<0,01)$.

Na sexta hipótese (H6) afirmou-se que a liderança dos diretores ou coordenadores influencia positivamente $\mathrm{e}$ indiretamente o desempenho das Pmies por meio da orientação empreendedora. Observou-se que há efeito indireto da liderança empreendedora sobre o desempenho, por meio da orientação empreendedora, estatisticamente significante ao nível de $1 \%(\Gamma=0,282, t=5,56, p<0,01)$.

$\mathrm{Na}$ sétima hipótese $(\mathrm{H} 7)$ afirmou-se que o capital humano dos diretores ou coordenadores influencia positivamente e diretamente 0 desempenho das Pmies privadas. Observou-se que não há efeito direto do capital humano sobre o desempenho das Pmies $(\Gamma=-0,053, t=0,42, p=0,672)$.

$\mathrm{Na}$ oitava hipótese (H8) afirmou-se que o capital humano dos diretores ou coordenadores influencia positivamente e indiretamente o desempenho das Pmies, por meio do capital social destes mesmos diretores ou coordenadores. Observou-se que não há efeito indireto do capital humano sobre o desempenho das Pmies, por meio do capital social, estatisticamente significante $(\Gamma=0,086, t=1,31, p=0,191)$. Registra-se que, pela análise do coeficiente de caminho entre o capital humano e o capital social, observa-se que há uma relação positiva e estatisticamente significante ao nível de $1 \%$ entre esses dois construtos $(\Gamma=0,617, t=10,356, p<0,01)$.

$\mathrm{Na}$ nona hipótese (H9) afirmou-se que o capital social dos diretores ou coordenadores influencia positivamente e diretamente 0 desempenho das Pmies privadas. Observou-se que não há efeito direto do capital social sobre o desempenho $(\Gamma=0,142, t=1,383, p=0,167)$. No quadro 12 apresenta-se a consolidação das hipóteses testadas.

Quadro 12 -

Consolidação das hipóteses testadas.

\begin{tabular}{|c|c|c|c|}
\hline \multicolumn{2}{|c|}{ Hipóteses } & Estatísticas & Resultados \\
\hline $\begin{array}{l}\text { H1: a orientação para a } \\
\text { positivamente e diretamente } \\
\text { privadas. }\end{array}$ & $\begin{array}{l}\text { aprendizagem influencia } \\
\text { desempenho das Pmies }\end{array}$ & $\begin{array}{c}(\Gamma=0,212, \\
t=1,92, \\
p=0,055)\end{array}$ & Não confirmada \\
\hline
\end{tabular}




\begin{tabular}{|c|c|c|}
\hline $\begin{array}{l}\text { H2: a orientação para a aprendizagem influencia } \\
\text { positivamente e indiretamente o desempenho das Pmies, por } \\
\text { meio da orientação para o mercado. }\end{array}$ & $\begin{array}{c}(\Gamma=-0,005 \\
t=0,10 \\
p=0,918)\end{array}$ & Não confirmada \\
\hline $\begin{array}{l}\text { H3: a orientação para o mercado influencia positivamente e } \\
\text { diretamente o desempenho das Pmies privadas. }\end{array}$ & $\begin{array}{c}(\Gamma=-0,016 \\
t=0,14, p= \\
0,889)\end{array}$ & Não confirmada \\
\hline $\begin{array}{l}\text { H4: a orientação empreendedora influencia positivamente e } \\
\text { indiretamente o desempenho das Pmies, por meio da } \\
\text { orientação para a aprendizagem. }\end{array}$ & $\begin{array}{l}(\Gamma=0,11 \\
t=1,91 \\
p<0,05)\end{array}$ & Confirmada \\
\hline $\begin{array}{l}\text { H5: a orientação empreendedora influencia positivamente e } \\
\text { diretamente o desempenho das Pmies privadas. }\end{array}$ & $\begin{array}{l}(\Gamma=0,461 \\
t=4,87 \\
p<0,01)\end{array}$ & Confirmada \\
\hline $\begin{array}{l}\text { H6: a liderança dos diretores/coordenadores influencia } \\
\text { positivamente e indiretamente o desempenho das Pmies, por } \\
\text { meio da orientação empreendedora. }\end{array}$ & $\begin{array}{l}(\Gamma=0,282 \\
t=5,56 \\
p<0,01)\end{array}$ & Confirmada \\
\hline $\begin{array}{l}\text { H7: o capital humano dos diretores/coordenadores influencia } \\
\text { positivamente e diretamente o desempenho das Pmies } \\
\text { privadas. }\end{array}$ & $\begin{array}{c}(\Gamma=-0,053 \\
t=0,42, p= \\
0,672)\end{array}$ & Não confirmada \\
\hline $\begin{array}{l}\text { H8: o capital humano dos diretores/coordenadores influencia } \\
\text { positivamente e indiretamente o desempenho das Pmies, por } \\
\text { meio do Capital Social destes mesmos } \\
\text { diretores/coordenadores. }\end{array}$ & $\begin{array}{l}(\Gamma=0,086 \\
t=1,31 \\
p=0,191)\end{array}$ & Não confirmada \\
\hline $\begin{array}{l}\text { H9: o capital social dos diretores/coordenadores influencia } \\
\text { positivamente e diretamente o desempenho das Pmies } \\
\text { privadas. }\end{array}$ & $\begin{array}{c}(\Gamma=0,142 \\
t=1,383, p= \\
0,167)\end{array}$ & Não confirmada \\
\hline
\end{tabular}

Fonte: resultados da pesquisa

Com o intuito de tornar aparente o encadeamento do processo analítico desse estudo, na figura 6 ilustra-se o desenho do modelo proposto a partir do referencial teórico, o desenho do modelo estrutural validado e os efeitos diretos e indiretos constatados.

Figura 6 -

Efeitos diretos e indiretos obtidos a partir do modelo proposto e validado 6 .

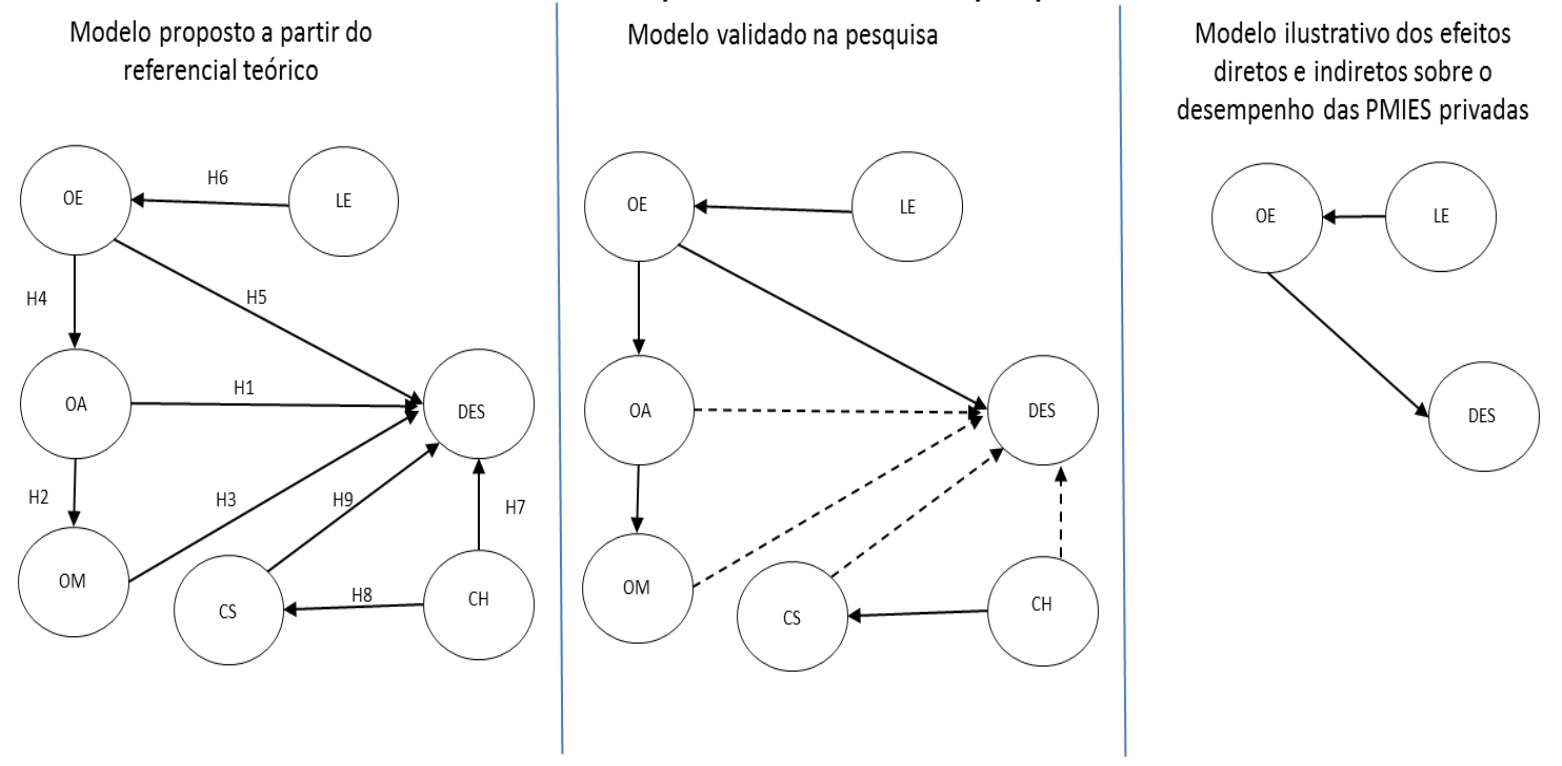

Fonte: resultados da pesquisa.

6 Nota: LE: liderança empreendedora; OE: orientação empreendedora; OA: orientação para a aprendizagem; OM: orientação para o mercado; CH: capital humano; CS: capital social e DES: desempenho; $\mathrm{H}_{1}, \mathrm{H}_{2}, \ldots, \mathrm{H}_{9}$ são as hipóteses testadas no estudo.

\begin{tabular}{|l|l|l|l|l|r|}
\hline Regae: Ver. Gest. Aval. Educ. & Santa Maria & v. 9 & n. 18 & Pub. contínua 2020 & p. 1-27
\end{tabular}


Ao confirmar a relevância do fator liderança e do fator empreendedor o estudo destaca o peso que o perfil da direção tem nessas organizações de ensino superior de pequeno e médio porte. Contudo, registre-se que essa relevância não é desprendida das condições de presença dos demais fatores no ambiente das Pmies, como capital humano, capital social, orientação para a aprendizagem e orientação para o mercado.

Por fim, pode-se dizer que essas condições atuam para a conformação de um ambiente propício ao perfil atitudinal e comportamental de liderança e empreendedorismo dos diretores como fatores de influência significante sobre o desempenho das Pmies.

\section{Considerações finais}

Por meio deste estudo expandiu-se a discussão sobre a modelagem do desempenho mediante o delineamento de um modelo mais robusto, com múltiplos fatores, considerando-os fatores que antecedem o desempenho organizacional. Além disso aprofundou-se na conceituação e caracterização do desempenho das instituições de ensino superior privadas, sob a ótica da discussão de modelos organizacionais.

Ao combinar teoria e dados no processo de construção e teste do modelo de desempenho das instituições de ensino superior, validou-se a escala para a mensuração do desempenho das Pmies, além de seis escalas de mensuração dos fatores de influência sobre o desempenho: orientação para o mercado, orientação para a aprendizagem, orientação empreendedora, liderança empreendedora, capital social e capital humano.

Por fim, destaca-se a constatação dos efeitos indiretos da liderança empreendedora no desempenho das Pmies, bem como a influência direta da orientação empreendedora no desempenho deste tipo específico de organização, que são as instituições de ensino superior privadas.

\section{Referências}

ABMES. Diagnóstico das pequenas e médias instituições de ensino superior privadas no Brasil: indicações para melhoria da competitividade. Estudos: Revista da Associação Brasileira de Mantenedoras de Ensino Superior, Brasília, v. 29, n. 41, 2014.

ACQUAAH, Moses. Managerial social capital, strategic and organizational performance in an emerging economy. Strategic Management Journal, v. 28, 2007, p. 1235-1255.

AGHION, Philippe; DEWATRIPONT, Mathias; HOXBY, Caroline; MAS-COLELL, Andreu; SAPIR, André. The governance and performance of universities: evidence from Europe and the US. Economic Policy, Sussex, 2010, p. 7-59.

ANTONI, Verner Luis. A relação entre orientação para o mercado e performance organizacional: um estudo nos cursos de bacharelado em administração da região Sul do Brasil. Florianópolis: UFSC, 2004. 213f. Tese de doutorado (Doutorado em Engenharia de Produção) - Universidade Federal de Santa Catarina.

BAKER, Willian; SINKULA James Michael. The synergistic effect of market orientation and learning orientation on organizational performance. Journal of the Academy of Marketing Science, Ruston, v. 27, 1999, p. 411-427.

BRASIL. Sinopses estatísticas da educação superior. Disponível em www.portal.inep.gov.br/superior-censosuperior. Acesso em 20 nov. 2019. 
CARUANA, Albert; RAMASESHAN, Balasubramanian; EWING, Michael. Market orientation and performance: a study of Australasian Universities. Malta: Curtin Business School, 1996.

CASTANHAR, Jose Cezar; DIAS, João Ferreira; ESPERANÇA, José Paulo. Orientação empreendedora, reconhecimento de oportunidades e desempenho em pequenas e médias empresas brasileiras: evidências de dois estudos de Caso. ENANPAD, 30, 2006, Salvador. Anais... Salvador: Anpad, 2006.

CHERUIYOT, Thomas Kimeli; MARU, Loice. Service quality and relative performance of public universities in East Africa. The TQM Journal, v. 25, n. 5, 2013, p. 533-546.

COHEN, Jacob. Statistical power analysis for the behavioral sciences. New York: Psychology Press, 1988.

COLOMBO, Massimo; GRILLI, Luca. Founder's human capital and the growth of new technology-based firms: a competence-based view. Research Policy, Örebro, v. 34, 2005, p. 795-816.

COVIN, Jeffrey Glenn; SLEVIN, Dennis Patrick. A conceptual model of entrepreneurship as firm behavior. Entrepreneurship: Theory \& Practice, Waco, v. 16, n. 1, 1990, p. 7-25.

COVIN, Jeffrey Glenn; SLEVIN, Dennis Patrick. Strategic management of small fi rms in hostile and benign environments. Strategic Management Journal, v. 10, n. 1, 1989, p. 7587.

DESS, Gregory; LUMPKIN, George Tom. The role of entrepreneurial orientation in stimulating effective corporate entrepreneurship. The Academy of Management Executive, New York, v. 19, n. 1, 2005, p. 147-156.

FALEIRO, Sandro Nero. A relação entre orientação para o mercado, orientação para a aprendizagem e inovação: o caso dos cursos de graduação em Administração filiados a Angrad. Porto Alegre: Ufrgs, 2001. 117f. Dissertação (Mestrado em Administração) Escola de Administração, Universidade Federal do Rio Grande do Sul.

FELÍCIO, Jorge Augusto; COUTO, Eduardo; CAIADO, Jorge. Human capital, social capital and organizational performance. Management Decision, v. 52, n. 2, 2014, p. 350-364.

FERNANDES, Daniel Von Der Heyde; SANTOS, Cristiane Pizzuti dos. Orientação empreendedora: um estudo sobre as consequências do empreendedorismo nas organizações. ERA eletrônica, v. 7, n. 1, 2008, p. 1-28.

FONTANELLE, Caio Júlio de Souza; HOELTGEBAUM, Marianne; SILVEIRA, Amélia. A influência do perfil empreendedor dos franqueados no desempenho organizacional. ENANPAD, 30, 2006, Salvador. Anais... Salvador: Anpad, 2006.

FORNELL, Claes; LARCKER, David. Evaluating structural equation models with unobservable variables and measurement error. Journal of Marketing Research, Chicago, v.18, n. 1, 1981, p. 39-50.

GARSON, David. Testing of assumption from statnotes: topics in multivariate analysis. Disponível em http://www2.chass.ncsu.edu/garson/PA765.statnote.html, 2014. Acesso e 5 nov. 2019.

GIMENO, Javier; FOLTA, Timothy; COOPER, Arnold; WOO, Carolyn. Survival of the fittest? Entrepreneurial human capital and the persistence of underperforming firms. Administrative Science Quarterly, v. 42, 1997, p. 750-783. 
GRÉGOIRE, Denis; NÖEL, Martin; DÉRY, Richard; BÉCHARD, Jean-Pierre. Is there conceptual convergence in entrepreneurship research? A co-citation analysis of frontiers of entrepreneurship research 1981-2004. Entrepreneurship: Theory \& Practice, New York v. 30, n. 3, 2006, p. 337-373.

HAIR, Joseph; ANDERSON, Rolph; TATHAM, Ronald; BLACK, William; BABIN, Barry. Análise multivariada de dados. Porto Alegre: Bookman, 2009.

HOELTGEBAUM, Marianne; SILVEIRA, Amélia; CAMARGO, Mario Sergio Gonçalves de. Análise do perfil empreendedor do fundador e seu sucessor em empresas familiares catarinenses. Revista Alcance, Itajaí, v. 14, n. 3, 2007, p. 427-445.

HURLEY, Robert; HULT, Tomas. Innovation, market orientation, and organizational learning: an integration and empirical examination. Journal of Marketing, Chicago, v. 62, 1998, p. $42-54$.

JAWORSKI, Bernard; KOHLI, Ajay. Market orientation: antecedents and consequences. Journal of Marketing, Chicago, v. 57, n. 3, 1993, p. 53-70.

LUMPKIN, George Tom; DESS, Gregory. Clarifying the entrepreneurial orientation construct and linking it to performance. The Academic of Management Review, Chicago, v. 21 , n. 1, 1996, p. 135-172.

MA, Jun; TODOROVIC, Zelimir. Making universities relevant: Market orientation as a dynamic capability within institutions of higher learning. Academy of Marketing Studies Journal, Guangdong, v. 15, n. 2, 2011, s/p.

MARSICK, Victoria; WATKINS, Karen. Demonstrating the value of an organization's learning culture: the dimensions of the learning organization questionnaire. Advances in Developing Human Resources, Oklahoma, v. 5, n. 2, 2003, p. 132-151.

MARTENS, Cristina Dai Prá; FREITAS, Henrique. Empreendedorismo no nível organizacional: um modelo conceitual para estudo da orientação empreendedora, suas dimensões e elementos. Revista Adm. MADE, São Paulo, v. 11, 2007, p. 15-44.

McCLELLAND, David Clarence. The achieving society. Princeton: D. Van Nostrand, 1961.

MENEZES, Elisabeth Aparecida Corrêa; GUIMARÃES, Tomas de Aquino; BIDO, Diógenes de Souza. Dimensões da aprendizagem em organizações: validação do dimensions of the learning organization questionnaire (DLOQ) no contexto brasileiro. RAM, Revista Administração Mackenzie, São Paulo, v. 12, n. 2, 2011, p. 4-29.

NAMAN, John; SLEVIN, Dennis. Entrepreneurship and the concept of fit: a model and empirical tests. Strategic Management Journal, v. 14, n. 2, 1993, p. 137-154.

NARVER, John; SLATER, Stanley. The effect of market orientation on business profitability. Journal of Marketing, Chicago, v. 54, n. 4, 1990, p. 20-35.

NARVER, John; SLATER, Stanley; MACLACHLAN, Douglas. Responsive and proactive market orientation and new product success. Journal of Product Innovation Management, Sta. Paul, Minnesota, v. 21, n. 5, 2004, p. 334-347.

RAUCH, Andreas; WIKLUND, Johan; LUMPKIN, George Tom; FRESE, Michael. Entrepreneurial orientation and business performance: cumulative empirical evidence. Entrepreneurship Theory and Practice, Syracuse, v. 33, n. 3, 2004, p. 761-788. 
REIS NETO, José Francisco dos; GALLEGo, Pablo Antonio Muñoz; SOUZA, Celso Correia de; RODRIGUES, Wesley Osvaldo Pradella. O papel da orientação empreendedora no relacionamento entre orientação para o mercado e desempenho empresarial: evidências das pequenas empresas do comércio. REAd, Porto Alegre, v. 74, n. 1, 2013, p. 115-138.

RINGLE, Christian; SILVA, Dirceu da; BIDO, Diógenes de Souza. Modelagem de equações estruturais com utilização do SmartPLS. Revista Brasileira de Marketing, São Paulo, v. 13, n. 2, 2014, p. 54-71.

SCHILDT, Henri; ZAHRA, Shaker; SILLANPÄÄ, Antti. Scholarly communities in entrepreneurship research: a co-citation analysis. Entrepreneurship: Theory \& Practice, New York, v. 30, n. 3, 2006, p. 399-415.

SCHMIDT, Serje; BOHNENBERGER, Maria Cristina. Perfil empreendedor e desempenho organizacional. RAC, Maringá, v. 13, n. 3, 2009, p. 450-467.

SOUZA NETO, Arcanjo Ferreira de; CORDEIRO, Adriana Tenório. Orientação empreendedora, incubação e redes de empresas vis-à-vis competências mercadológicas e desempenho: um estudo em empresas de base tecnológica. ENANPAD, 30, 2006, Salvador. Anais ... Salvador: Anpad, 2006.

STEVENS, James. Applied multivariate for the social sciences. New Jersey: Lawrence Erlbaum, 1996.

TARABISHY, Ayman; SOLOMON, George; FERNALD, Lloyd; SASHKIN, Marshall. The entrepreneurial leader's impact on the organization's performance in dynamic markets. The Journal of Private Equity, Londres, v. 8, n.4, 2005, p. 20-29.

VEIT, Mara Regina; GONÇALVES FILHO, Cid. Mensuração do perfil do potencial empreendedor e seu impacto no desempenho das pequenas empresas. ENANPAD, 31, 2007, Rio de Janeiro. Anais... Rio de Janeiro: Anpad, 2007.

YANG, Baiyin. Identifying valid and reliable measures for dimensions of a learning culture. Developing Human Resources, Oklahoma, v. 5, n. 2, 2003, p. 152-162.

ZAHRA, Shaker; COVIN, Jeffrey Glenn. Contextual influences on the corporate entrepreneurship - performance relationship: a longitudinal analysis. Journal of Business Venturing, Bloomington, v. 10, n. 1, 1995, p. 43-58.

Diogo Martins Gonçalves de Morais é professor na Fundação Salvador Arena.

Orcid: http://orcid.org/0000-0001-5681-4044.

Endereço: Estrada dos Alvarengas, 4001 - 09850-550 - São Bernardo do Campo SP - Brasil.

E-mail: pro7113@cefsa.edu.br.

Júlio Francisco Blumetti Facó é professor na Universidade Federal do ABC.

Orcid: http://orcid.org/0000-0002-8155-5547.

Endereço: Alameda da Universidade, s/no - 09606-045 - São Bernardo do Campo SP - Brasil.

E-mail: julio.faco@ufabc.edu.br. 
Maria do Carmo Romeiro é professora na Universidade Municipal de São Caetano do Sul.

Orcid: https://orcid.org/0000-0002-3158-7903.

Endereço: Rua Manoel Coelho, 600 - 09510-101 - São Caetano do Sul - SP - Brasil. E-mail: mromeiro@uscs.edu.br.

Recebido em 8 de julho de 2020.

Aceito em 16 de setembro de 2020.

(c) (i) $(-)$ 